\title{
Influence of methodological choices on maintenance and replacement in building LCA
}

\author{
Nicolas Francart ${ }^{1}$ (1) $\cdot$ Torun Widström $^{2} \cdot$ Tove Malmqvist $^{1}$
}

Received: 25 February 2021 / Accepted: 28 September 2021 / Published online: 1 November 2021

(c) The Author(s) 2021

\begin{abstract}
Purpose Previous life cycle assessments (LCAs) of buildings and building components show a broad range of values for the impact of maintenance and replacement, some highlighting these operations as major hotspots while others consider them insignificant. This article highlights methodological aspects explaining this discrepancy. The influence of three aspects is investigated further in a case study of façade materials: the reference study period (RSP), service life data, and the use of a round-up number of operations or annualized impacts.

Methods A comparative LCA of seven façade alternatives is carried out as an illustrative case study. For each alternative, global warming potential (GWP) is calculated using three possible RSPs, four possible material service lives (one from industry practitioners and low, standard and high values from a generic database), and two possible calculation methods (round-up or annualized impacts).

Results and discussion While the same façade alternative had the lowest GWP in all cases, different methodological choices significantly affected the GWP and respective ranking of other alternatives. Some alternatives showed a significant increase in GWP over longer RSPs, while others were still dominated by the impact of initial production after 200 years. In nearly all cases, generic service life data lead to a higher GWP than data from industry practitioners. Major discrepancies were found between generic and practitioner data in some cases, e.g., for the brick façade. In most cases, annualized impacts led to a slightly lower (or equal) GWP than using a round-up number of operations. However, when a major operation happens shortly before the end of the RSP, the annualized method leads to considerably lower GWP.

Conclusions Maintenance and replacement are rarely significant over a 50-year RSP but sometimes become hotspots over longer RSPs. Using round-up operations or annualized impacts does not make much difference in average, but leads to significantly different results in specific cases. As building LCA enters certification and regulation, there is a need to harmonize such methodological choices, as they affect LCA results, hotspot identification, and recommendations. Discrepancies in service life data also call for the gathering of reliable data.
\end{abstract}

Keywords Building $\cdot$ Maintenance $\cdot$ Replacement $\cdot$ Embodied $\cdot$ Service life $\cdot$ Methodology

\section{Introduction}

Various estimates indicate that buildings are responsible for $20-40 \%$ of global greenhouse gases (GHG) emissions (depending on the scope of the building sector and the

Communicated by Holger Wallbaum.

Nicolas Francart

francart@kth.se

1 Department of Sustainable Development, Environmental Science and Engineering (SEED), KTH Royal Institute of Technology, Stockholm, Sweden

2 Department of Civil and Architectural Engineering, KTH Royal Institute of Technology, Stockholm, Sweden accounting of upstream emissions) (International Energy Agency 2013; Lucon et al. 2014; United Nations Environment Programme and International Energy Agency 2017). It is therefore necessary to carefully design new buildings as well as refurbishment operations in order to minimize life cycle GHG emissions, in line with climate change mitigation targets such as the Paris agreement (United Nations Framework Convention on Climate Change 2015).

Life cycle assessment (LCA) is a widely studied tool to assess global warming potential (GWP) in the building sector (Hauschild et al. 2017). LCA is used in certification schemes such as LEED and BREEAM and is starting to be adopted in regulation. In Sweden, a mandatory declaration of climate impact for new buildings will be introduced in 
2022. At first, it will be limited to the product stage, transportation, and on-site processes, but a future introduction of other life cycle stages and of limit values is considered (Swedish National Board of Housing, Building and Planning 2020). Although operational energy use has traditionally been highlighted as the main hotspot of GWP in the life cycle of most buildings, recent studies indicate a rising importance of the relative contribution of embodied emissions, i.e., emissions caused by the production, transport, installation, maintenance, and disposal of construction materials. This change is partly explained by improvements in energy performance and a decarbonization of the energy supply (Anand and Amor 2017; Birgisdottir et al. 2017; Blengini and Di Carlo 2010; Buyle et al. 2013; Chastas et al. 2018). Therefore, it becomes increasingly important to account comprehensively for embodied emissions in building LCA, including the initial production of materials as well as processes such as future maintenance and replacement. However, Pomponi and Moncaster (2016) reviewed academic studies of embodied carbon mitigation strategies and showed that most studies overlook maintenance and replacement. De Wolf et al. (2017) also showed that practitioners often omit use phase embodied carbon in their assessments, due to uncertainty or a lack of data, time, or understanding of the impact. Moreover, despite the existence of standards such as the European Norm EN 15978, a broad range of methodological choices remains possible regarding, e.g., the modeling of future maintenance and replacement processes (Birgisdottir et al. 2017; European Standards 2011; Frischknecht et al. 2019, 2020). This paper investigates the modeling of maintenance and replacement of materials in building LCA. It builds upon a previous conference article which introduced the issue and included a case study of roofing materials (Francart and Malmqvist 2020). The present paper considers a different building element (the façade) and uses a different approach to investigate variability related to the choice of reference study period (RSP), calculation method, and service life data source.

\section{Literature review}

The relative contribution of maintenance and replacement processes in life cycle GWP shows a great variability between published case studies, from $1 \%$ or less (Allacker et al. 2019; Cuéllar-Franca and Azapagic 2012; Kofoworola and Gheewala 2008, 2009; Lavagna et al. 2018; Peuportier et al. 2013; Roh et al. 2018) up to a third or a half of total life cycle emissions (Gomes et al. 2018; Hoxha et al. 2016). Frischknecht et al. (2020) showed that significant discrepancies exist between assessments using methods from different countries, even when they assess the same building. A recent statistical study by Goulouti et al. (2020) found that maintenance and replacement processes account for 14-36\% of life cycle GWP at the building level. Studies focusing on embodied emissions show that, in some cases, maintenance and replacement processes can account for about half of life cycle embodied emissions (Häfliger et al. 2017; Petrovic et al. 2019).

Several potential reasons can explain this broad range of values. The first one is differences in the energy performances of the case study buildings. In the case of low-energy buildings, operational energy use is considerably lower and the relative share of embodied emissions is larger than in conventional buildings. As a result, the share of GWP from maintenance and replacement is also larger than in conventional buildings. Blengini and Di Carlo (2010) conclude that, for low-energy buildings, the construction of the building frame is the main hotspot of environmental impacts, but maintenance processes can significantly contribute to several impact categories. Some LCA studies showing a comparatively large share of GWP for maintenance and replacement focus on low-energy buildings (Gomes et al. 2018; Hoxha et al. 2016).

A second possible reason is a difference in assumptions about future scenarios. Prospective LCA studies that assume future improvements in production or recycling technologies for construction materials might show lower impacts from maintenance and replacement (Alig et al. 2020). Conversely, studies that assume a future decarbonized energy mix will show lower impacts from operational energy use and proportionally higher embodied impacts (Göswein et al. 2020; Peñaloza et al. 2016).

A third possible reason is a difference in the scope of maintenance and replacement processes considered. The European Norm EN 15978 distinguishes between processes of maintenance (module B2), repairs (B3), replacement (B4), and refurbishment (B5). However, not all studies are equally comprehensive in their coverage of these modules. Thibodeau et al. (2019) review building rehabilitation case studies and mention that $83 \%$ of the studies included module B4, 20\% included B2, and none included B3. De Wolf et al. (2017) mention that modules B2, B3, and B5 are often omitted in practice. Moreover, the scope of what is included under each of these labels is ambiguous, which hinders comparability, as different studies use different scopes. Chastas et al. (2018) review 95 case studies and mention that the scope of what is included in modules B2-B5 is generally not clearly defined. Dixit (2018) highlights that many studies are unclear about whether they cover maintenance, replacement, repairs, and/ or retrofit operations and that differences in results can be partly explained by differences in the types of operations considered. Finally, studies differ in terms of what elements are considered to be maintained or replaced. Some materials present in small amounts might be disregarded 
even though they are responsible for a significant share of environmental impacts (Hong et al. 2015; Kellenberger and Althaus 2009). Some elements such as carpets, paint, doors, and windows might be disregarded because they cause a small share of initial impacts, but they can become a hotspot of impacts during operation due to their high frequency of replacement (Carlisle and Friedlander 2016; Colli et al. 2018; Eberhardt et al. 2019; Häfliger et al. 2017; Junnila et al. 2006; Kofoworola and Gheewala 2009; Minne and Crittenden 2015; Rauf and Crawford 2015; Scheuer et al. 2003).

A fourth possible reason is a difference in reference study periods (RSP) between studies. Studies over longer RSPs have a longer operational phase and therefore higher impacts for both operational energy use and maintenance/ replacement. Goulouti et al. (2020) show that the choice of RSP influences what building elements contribute most to uncertainty on the results. Vilches et al. (2017) review LCA of refurbishment operations and point out that RSPs varied from 50 to 150 years. Häfliger et al. (2017) and Hoxha et al. (2016) use several RSPs in their assessments and show that the relative contribution of maintenance and replacement increases with the RSP. Some studies focusing on particular building elements use very long RSPs: Mequignon et al. (2013) study an external wall over 300 years and estimate that replacements and maintenance contribute to $75 \%$ of GWP.

A fifth possible reason to explain this discrepancy is a difference in the assumed frequency and extent of maintenance and replacement processes. Most practitioners would usually use reference service lives (RSL), generic values found in databases. However, there might be large discrepancies between RSL values found in different databases. Dixit (2018) and Hoxha et. al. (2014) review service life values from a number of references, and both the range of values and the standard deviation are very high for most types of materials. Moreover, the actual service life of materials depends on use and exposure conditions. Several methods have been used to come up with an estimated service life (ESL) for construction materials, taking into account exposure and use conditions. The ISO 15686-8 norm recommends using the "factor method." The ESL is then calculated by multiplying a generic RSL by 7 different correction factors representing the influence of material quality, design, and execution, exposure to indoor and outdoor environment, use conditions, and maintenance procedures. Other methods include deterministic approaches, which calculate the ESL based on the physical properties of materials and on use conditions (e.g., load and exposure), and stochastic approaches, which determine a probability distribution for the service life based on statistical analyses of the degradation of components in real use cases (Grant et al. 2014; Silvestre et al. 2015). Stochastic approaches usually provide an average service life rather than a case-specific value, but they can be combined with the aforementioned factor method to provide an ESL based on a narrower range of parameters and fewer assumptions (Aktas and Bilec 2012). Finally, Dixit (2018) mentions that replacements can be driven by other factors than technical service life, e.g., changes in ownership, technological or aesthetic trends, or replacement of materials embedded with each other.

Finally, discrepancies can be explained by the choice of method to calculate the number of maintenance and replacement operations. Some assessments calculate a "round-up" number of operations, corresponding to the actual number of operations expected to happen during the RSP. Thus, an element with a service life of 30 years is replaced 3 times over 100 years. This approach is prescribed, e.g., by the EN 15978 norm and the DGNB certification system (European Standards 2011; German Sustainable Building Council 2018). Other assessments use an "annualized" number of operations, where the impact of each type of operation is divided by its period of occurrence and multiplied by the RSP (minus the service life of the initial component). This is equivalent to using a fractional number of replacements: Over 100 years, an element with a service life of 30 years is replaced 2.33 times. This method has been used for instance in Switzerland, Norway, and France (French Ministry for the Ecological Transition and French Ministry for Territorial Cohesion 2017; Goulouti et al. 2020; Standard Norge 2017). The present article investigates the influence of the latter three aspects: the RSP, the choice of data source of material service lives, and the choice of round-up or annualized modeling for calculating the number of operations.

\section{Aim}

The objective of this article is to investigate to what extent methodological choices and assumptions made by LCA practitioners regarding maintenance and replacement influence the calculated environmental impact of building elements. In order to narrow down the scope and focus on a small number of relevant parameters, the study is limited to façade materials. Façades are suitable objects of study because they can be made of a broad variety of materials, with different service lives and maintenance needs. Furthermore, the study is limited to GWP as the only environmental impact category, because it is commonly used and environmental data are readily available. GWP has been used as a proxy for several other environmental impact categories, although not all impact categories correlate strongly with GWP (Heinonen et al. 2016; Laurent et al. 2012). The following research questions are examined:

RQ1. For what choices of RSP do maintenance and replacement processes significantly contribute to the results of a comparative LCA of façade materials? 
RQ2. To what extent can the choice of data source for the service lives of façade materials influence the results of a comparative LCA?

RQ3. To what extent can different methodological approaches to calculate GWP from maintenance and replacement influence the results of a comparative LCA of façade materials?

\section{Method}

This section provides an overview of the method used to address the research questions. A more detailed description of methodological choices and data sources is provided as supplementary material.

\subsection{Object of study}

The goal of the assessment is to assess and compare the life cycle GWP of the following seven alternatives for the façade of an apartment building, in various maintenance and replacement scenarios and over various RSPs:

1. A ventilated render façade on a steel structure

2. A similar ventilated render façade on an aluminum structure $^{1}$

3. A non-ventilated render system

4. A brick cladding

5. Fiber cement façade panels

6. Cedar clapboard panels

7. Pine/spruce cover boarding

All alternatives represent real products on the market. The composition of the wall behind the façade is assumed to be the same in all alternatives. The only exception is the insulation layer. The non-ventilated render façade includes external insulation. In order to ensure that the façades fulfill the same function in terms of thermal conductivity, a layer of insulation was added to the other alternatives. The performance of the various alternatives along other criteria (e.g., acoustics, thermal mass) was not considered. The composition of each façade alternative is presented in Table 1 and in more detail in the supplementary material.

\subsection{LCA}

A comparative attributional LCA of the seven façade alternatives was carried out (Goldstein and Rasmussen 2017).

\footnotetext{
${ }^{1}$ According to the manufacturer, the steel structure is more representative of the Swedish market and the aluminum structure is more common in North America.
}

The functional unit is $1 \mathrm{~m}^{2}$ of façade on a seven-story residential building in Sweden, over the chosen RSP. The number of stories is common for new developments in urbanized areas in Sweden and is specified because it affects material amounts for some of the alternatives (taller façades require better wind resistance). The assessment was performed following guidelines from the EN 15978 norm (European Standards 2011) and covers the following life cycle stages:

- A1-A3: production of construction materials

- A4: transport of materials to the construction site

- A5: on-site processes. In this study, only the wastage of materials is taken into account

- B1: impacts during use. In this study, this only includes carbon uptake by carbonation in cement-containing materials (European Committee for Standardization 2017, 2019)

- B2-B4: maintenance and replacement of materials

- C1-C4: end of life, waste treatment and disposal

A total of 24 assessments are performed for each façade alternative, corresponding to each possible combination of the following methodological choices:

1. The RSP: assessments are carried out over 50 years, 100 years, and 200 years respectively. Fifty years is a common RSP for building LCA in many tools and European countries, used for instance in the EU Level(s) assessment framework (Dodd et al. 2021). Two hundred years corresponds to the longest replacement period among the scenarios and alternatives considered. In this study, the RSP is seen as a methodological choice depending on the LCA tool or framework used and is not necessarily identical to the building's technical service life. For instance, after a RSP of 50 years, the building might remain in operation and start a different life cycle, e.g., after undergoing refurbishment. This aspect is discussed further in Sect. 6.1.

2. The data source for service lives: The aim of this analysis is to compare different options available for LCA practitioners to select maintenance and replacement scenarios. As such, the focus is on examining differences between existing service life estimates from various sources, without arguing for which source is more realistic. However, the plausibility of various replacement scenarios is addressed in discussion. Assessments are first carried out using service life data obtained from industry practitioners and technical documentation on the manufacturers' websites. Three additional assessments are then performed based on generic service lives from a report by Erlandsson and Holm (2015). The report compiles previously existing service life data representative of the Swedish context. For each material type, it presents a low value corresponding to a pessimistic service life or a highly exposed material, a standard value, 
Table 1 Façade alternatives studied
Façade alternative

Ventilated render +
aluminum

Ventilated render + steel

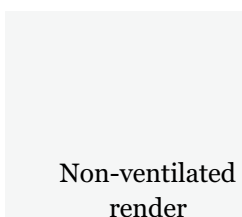

render

Brick cladding

$138 \mathrm{~kg}$ bricks, $70 \mathrm{~kg}$ cement mortar, 0.2 $\mathrm{kg}$ steel ties. Additional insulation: 30 $\mathrm{mm}$ thick rock wool panel.

$2.4 \mathrm{~kg}$ hydrophobic render, $4.5 \mathrm{~kg}$ acrylic plaster, $0.16 \mathrm{~kg}$ glass fiber mesh, $6.3 \mathrm{~kg}$ carrier board, $3.1 \mathrm{~kg}$ aluminum profiles, $0.61 \mathrm{~kg}$ steel brackets, $0.06 \mathrm{~kg}$ screws. Additional insulation: $30 \mathrm{~mm}$ thick rock wool panel.

$2.4 \mathrm{~kg}$ hydrophobic render, $4.5 \mathrm{~kg}$ acrylic plaster, $0.16 \mathrm{~kg}$ glass fiber mesh, $6.3 \mathrm{~kg}$ carrier board, $2 \mathrm{~kg}$ steel profiles, $0.06 \mathrm{~kg}$ screws. Additional insulation: $30 \mathrm{~mm}$ thick rock wool panel.

$25 \mathrm{~kg}$ top layer lime-cement render, 27 $\mathrm{kg}$ base layer lime-cement render, 1.55 $\mathrm{kg}$ steel mesh, $2.75 \mathrm{~kg}$ glass wool, 0.02 kg screws.

$11.6 \mathrm{~kg}$ fiber cement panel, $0.3 \mathrm{~kg}$ EPDM underlay, $2.9 \mathrm{~kg}$ steel profile, $0.03 \mathrm{~kg}$ screws. Additional insulation: $30 \mathrm{~mm}$ thick rock wool panel.

Fiber cement

$5.7 \mathrm{~kg}$ cedar panel, $1.8 \mathrm{~kg}$ timber battens, $0.06 \mathrm{~kg}$ nails. Additional insulation: $30 \mathrm{~mm}$ thick rock wool panel.

\section{Cedar}

$13.6 \mathrm{~kg}$ heat-treated pine panel, $0.21 \mathrm{~kg}$ acrylic paint, $0.175 \mathrm{~kg}$ screws, $1.8 \mathrm{~kg}$ timber battens. Additional insulation: $30 \mathrm{~mm}$ thick rock wool panel.

Figure

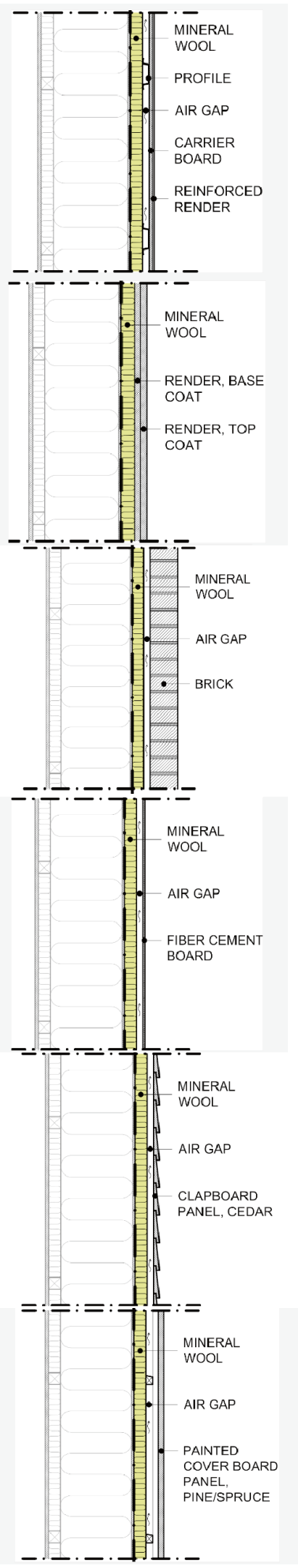


and a high value corresponding to an optimistic service life or a sheltered material.

3. The method used to calculate the impact of maintenance and replacement. First, the analysis is carried out with the roundup method, which considers the number of maintenance and replacement operations that would actually happen during the RSP:

$N_{\text {round,replacements }}=\operatorname{Roundup}\left(\frac{T}{t}-1\right)$

$G W P_{\text {round,replacements }}=N_{\text {round,replacements }} \times G W P_{\text {per operation }}$

where $N_{\text {round,replacements }}$ is the number of operations, $T$ is the RSP, $t$ is the component's service life, Roundup is the rounding up function, $G W P_{\text {round,replacements }}$ is the total impact of replacements, and $G W P_{\text {per operation }}$ is the impact of a single operation. The minus one term in the number of replacements corresponds to the initial installation, taken into account in A1-A3. This approach is consistent with, e.g., EN 15978 (European Standards 2011). Then, a second analysis is carried out with the annualized method. A yearly GWP value is calculated for each maintenance and replacement operation by dividing the GWP of each operation by the period at which it occurs:

$G W P_{\text {yearly }}=\frac{G W P_{\text {per operation }}}{t}$

$G W P_{\text {annualized,replacements }}=G W P_{\text {yearly }} \times(T-t)$

In this case, for an element with a service life of 30 years, no replacement happens during the first 30 years, and for each subsequent year a thirtieth of the GWP of this element is added. ${ }^{2}$

\subsection{Data gathering}

This study deliberately adopted a practice-oriented approach and was carried out in collaboration with industry practitioners. The alternatives chosen for comparison were meant to represent façade solutions that are common on the Swedish market, according to industry practitioners. They represent common practice for various industry branches, rather than best practice solutions.

\footnotetext{
2 These formulae are slightly modified when replacement and maintenance periods overlap. This would be the case for instance for a painted panel with a service life of 45 years repainted every 12 years. Whenever the panel is replaced, the new panel has a fresh coat of paint, which resets the repainting period. With the round up method, the number of repainting operations within each replacement period is first calculated. Then, repainting operations after the last replacement are added. Over 200 years, there will be 4 panel replacements. There are 3 repainting operations in 45 years, so 12 repainting operations in 180 years. One more repainting would happen in the last 20 years. With the annualized method, the annualized impact of repainting is ignored for the first 12 years after each replacement, so it would be included for years 13-45, 58-90, 103-135, 148-180 and 193-200.
}

The composition of each façade alternative as well as information on maintenance processes and material service lives were obtained by directly asking manufacturers whenever possible, in order to reflect the perspectives of practitioners. When data could not be obtained from practitioners, they were taken from technical documentation found on the manufacturer's website. The supplementary material provides more detail about data sources.

In addition to service life data obtained from practitioners, an analysis was carried out using generic service life data found in a Swedish report, for the purpose of comparison (Erlandsson and Holm 2015). This report compiles existing service life data from grey literature and proposes service life values for each material depending on whether the material is used under standard conditions, particularly exposed or protected. These values were used as standard, low, and high generic values for the maintenance and replacement periods, respectively. In all scenarios, when a façade reaches the end of its assumed service life, all non-structural parts of the façade are considered to be replaced. The "low service lives" (resp. "high service lives") scenario in the study uses the shortest (resp. longest) maintenance and replacement periods, in order to explore extreme best- and worst-case scenarios. However, it should be noted that in real cases, a short maintenance period is likely to be associated with a longer replacement period, and vice versa, as a component that is maintained often is likely to last longer (see, e.g., Carlisle and Friedlander 2016). The maintenance and replacement periods used in various scenarios are summarized in Table 2.

For the selection of environmental data, a priority order was established, following the recommendation in EN 15978 that "assessments should be made using data and information that most precisely represents the object of assessment and the time of the assessment" (European Standards 2011). Environmental Product Declarations (EPDs) for the specific products studied were used in priority. When this was not possible, data were selected from the Swedish tool BM (Byggsektorns Miljöberäkningsverktyg, i.e., Building Sector Environmental Calculation Tool, IVL Swedish Environmental Institute 2018). Data from the BM tool are representative for products used on the Swedish market. When no other suitable data were available, data were taken from the Ökobau database (German Federal Ministry of the Interior Building and Community 2020). More details are provided in the supplementary material.

\section{Results}

\subsection{Base case: LCA using service lives obtained from practitioners}

\subsubsection{Ranking of alternatives over different RSPs}

A first analysis (base case) was carried out using the round-up method and service life data from practitioners. Figures 1, 2, and 3 illustrate the life cycle GWP of all alternatives over a 


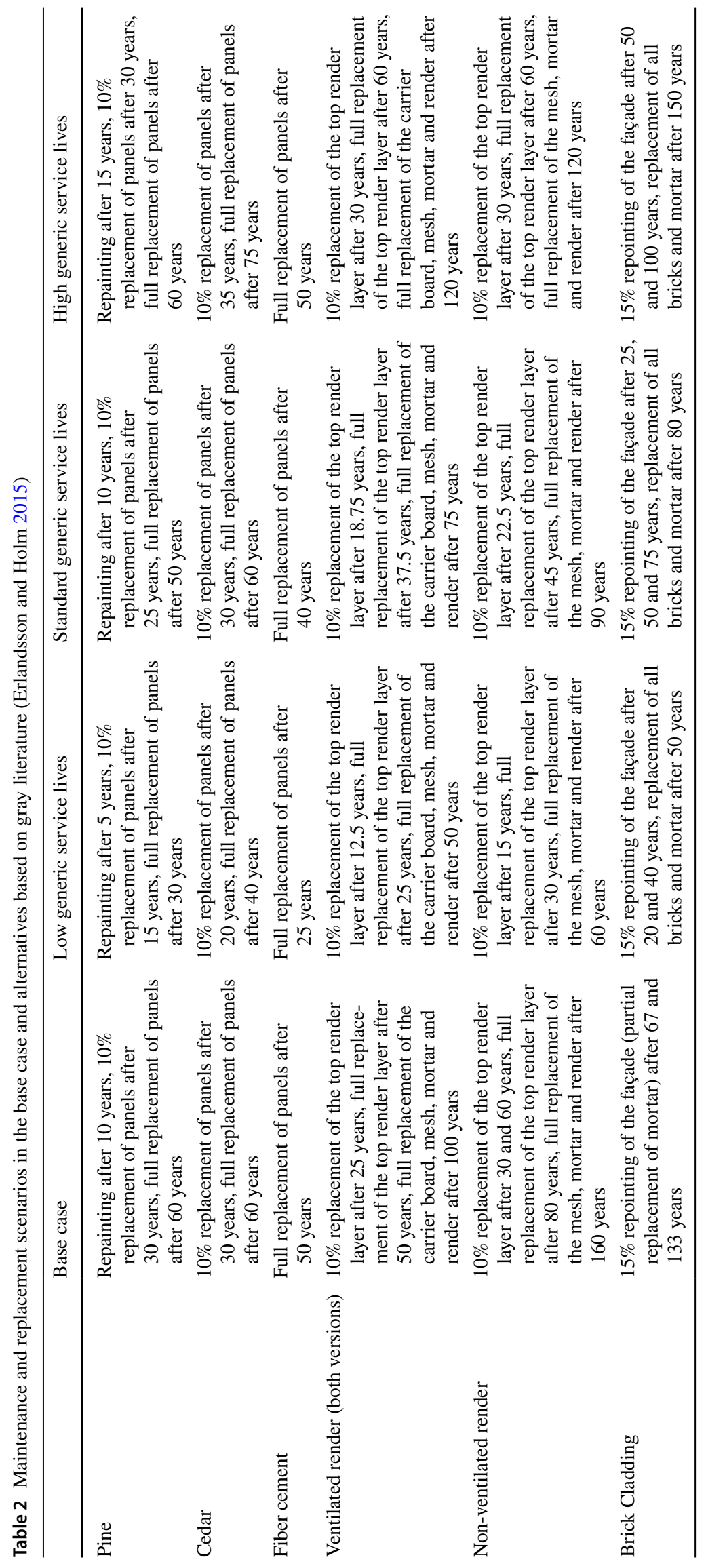


Fig. 1 Life cycle GWP of all façade alternatives over 50 years

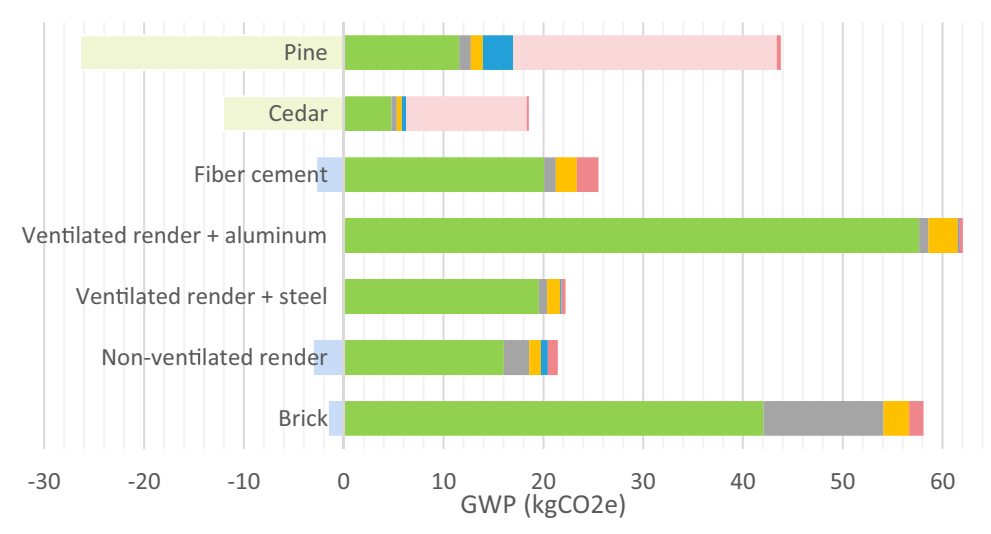

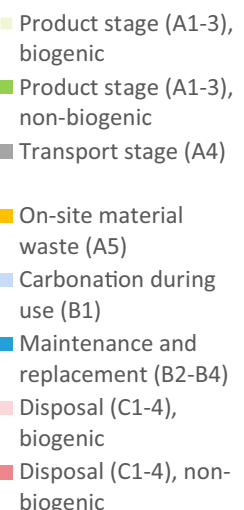

RSP of 50, 100, and 200 years respectively. For wood products, biogenic and non-biogenic GWP are reported separately for transparency. The negative biogenic GWP in module A due to the uptake of $\mathrm{CO}_{2}$ during tree growth is always compensated by an identical release of $\mathrm{CO}_{2}$ in module $\mathrm{C}$. Since some modules show a negative GWP, the length of the bars does not directly indicate the ranking of alternatives in terms of GWP.

The RSP significantly influences the ranking of alternatives in terms of life cycle GWP, although in all cases, the cedar façade has the lowest GWP and the ventilated render façade with aluminum profiles the highest. In particular, the pine façade ranks significantly worse when considering longer RSPs, and the brick façade significantly better.

\subsubsection{Contributions from various life cycle stages}

The respective contributions of each life cycle stage to life cycle GWP significantly differed depending on the alternative and the RSP. In the case of the brick façade and the ventilated render façade with aluminum profiles, the initial production of materials (modules A1-A3) still accounted for three quarters of life cycle GWP after 200 years. This indicates that the initial production of materials that are never replaced might, in some cases, still dominate life cycle GWP even over long RSPs.

In other cases, maintenance and replacement processes (modules B2-B4) played a significant role over a 200 years RSP (43-77\% of life cycle GWP). Over 100 years, maintenance and replacement are still the main contributors to life cycle GWP for the pine façade (57\%) and make a significant contribution for the cedar, non-ventilated render, and fiber cement façades (34-47\%). However, they only make small contributions for the ventilated render and brick facades. Over a 50-year RSP, modules B2-B4 make a negligible contribution to life cycle GWP for all alternatives except for the pine façade, where they account for $17 \%$ of GWP. This indicates that the choice of RSP considerably influences whether maintenance and replacement processes would be considered an important hotspot of GWP.

\subsubsection{Contributions from various materials and processes}

The analysis of GWP hotspots can be complemented by considering what materials and processes are the main contributors to GWP for each alternative. For the pine façade, the panels always represent above $70 \%$ of the life cycle GWP, paint another $13 \%$ and battens $7 \%$. It is noteworthy that the calculated GWP of the two wood façades differs significantly. The pine façade shows rather high emissions over 200 years, whereas the cedar façade retains a comparatively low GWP. This is partly due to lower material amounts, as the cedar clapboard panels weigh less than half as much as the pine cover panels. Moreover, cedar has a lower emission factor than pine (according to their respective EPDs), and the cedar panels do not require paint.

It is also interesting to compare the respective performances of the two ventilated render façades. The façades are produced by the same company (in different countries) and are identical, except for the types of metal profiles used. In the façade with aluminum profiles, the production and installation of the profiles (modules A1-A5) contributes to $57-72 \%$ of life cycle GWP over 200 and 50 years, respectively. The corresponding values for the steel profiles are 16-29\%. As a result, the aluminum alternative shows a considerably higher GWP than the steel alternative. The difference is due to the fact that aluminum profiles are $60 \%$ heavier than steel profiles and have a 4.6 times higher emission factor per $\mathrm{kg}$. This suggests that there can be considerable differences in life cycle GWP between technical alternatives for the same façade solution. ${ }^{3}$ The non-ventilated render façade uses a different technique altogether, with thicker layers of render. Since render is replaced over time, the non-ventilated render façade also shows higher emissions in modules B2-B4 from render replacement.

\footnotetext{
${ }^{3}$ Render for the ventilated render façade is delivered in an already carbonated form; therefore, it was assumed that no further carbonation happens in module B1.
} 
Fig. 2 Life cycle GWP of all façade alternatives over 100 years

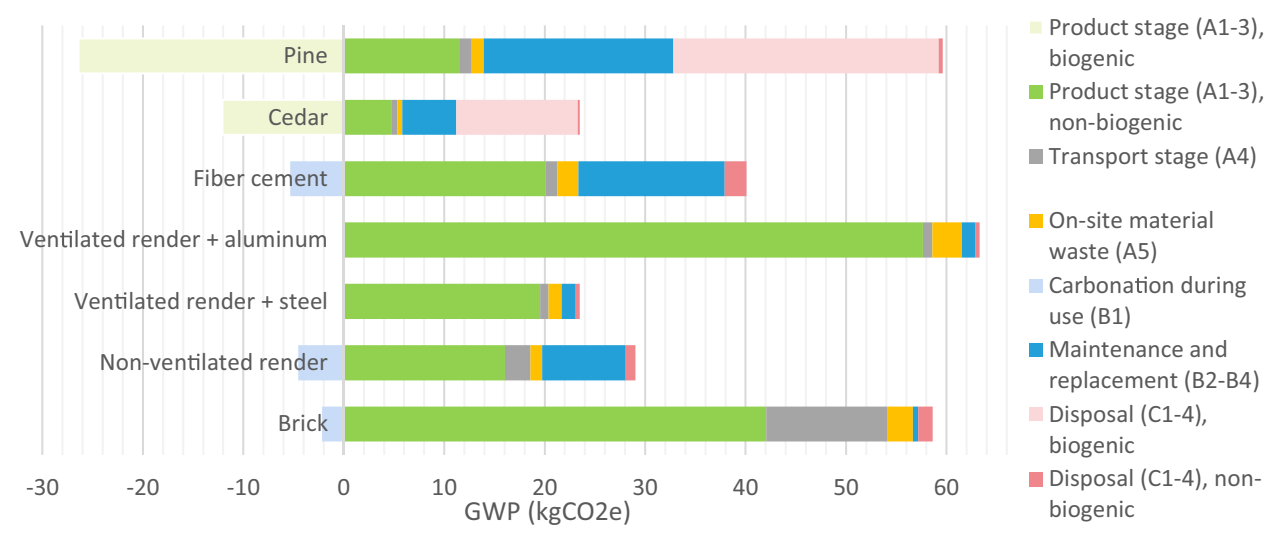

For the brick façade, bricks amount for about $70 \%$ of life cycle GWP and mortar for about $30 \%$. Since bricks are never replaced during 200 years in the base case, the only contribution to modules B2-B4 is repointing (partial replacement of mortar). For the fiber cement panels, initially, the panels and the steel profiles both contribute for about $40 \%$ of life cycle GWP. However, over a longer RSP, panels become the main contributor to GWP and cause about two-thirds of life cycle GWP over 200 years.

\subsection{LCA using generic service lives from the literature}

The first analysis relied on service lives obtained from technical documentation and dialogue with practitioners. For the purpose of comparison, a second analysis was carried out based on generic maintenance and replacement periods from Erlandsson and Holm (2015) (presented in the three "generic service lives" columns in Table 2). The results are shown in Fig. 4 for different RSPs. In each case, GWP is shown both for the full RSP and per year (i.e. normalized with the RSP).

In some cases, there is little to no difference in life cycle GWP when using different service life values. This can be due to the fact that for some alternatives the service life values in the base scenario are very close or even identical to service life values in one of the alternative scenarios. Even when service life values are different, the round-up number of replacements might be identical. However, for some alternatives, there are considerable differences between different replacement scenarios, especially over longer RSPs. For the brick façade, the impact over 200 years calculated with low generic service lives is four times higher than in the base case. Significant differences are also observed for the non-ventilated render façade (twice higher GWP than in the base case over 200 years), followed by the fiber cement façade, the pine façade, and the ventilated render façade with steel profiles (all about 1.8 times higher GWP when using low generic service lives).

A closer look at the service life values shows that, in most cases, service lives obtained from manufacturers and technical documentation are higher than standard generic service lives from the literature, with the exception of the cedar façade. In some cases, service lives from manufacturers are even higher than the high generic service lives. This is particularly noteworthy for the brick façade, where the base replacement scenario uses considerably higher service lives than even the high generic service lives from Erlandsson and Holm (2015).
Fig. 3 Life cycle GWP of all façade alternatives over 200 years

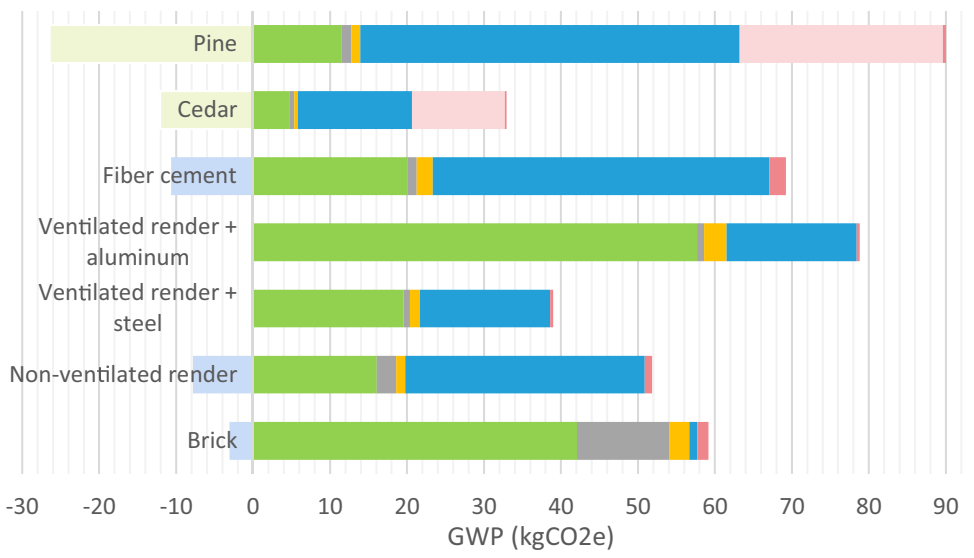

Product stage (A1-3), biogenic

aroduct stage (A1-3), non-biogenic

Transport stage (A4)

- On-site material waste (A5)

Carbonation during use (B1)

Maintenance and replacement (B2-B4)

Disposal (C1-4), biogenic

nisposal (C1-4), nonbiogenic 
Table 3 Relative change in life cycle GWP when using annualized impacts for replacement instead of the round-up method. Darker cells correspond to larger changes

\begin{tabular}{|c|c|c|c|c|c|}
\hline Brick & $\begin{array}{l}\text { Non- } \\
\text { ventilated } \\
\text { render }\end{array}$ & $\begin{array}{l}\text { Ventilated } \\
\text { render }+ \\
\text { steel } \\
\text { profiles }\end{array}$ & $\begin{array}{l}\text { Ventilated } \\
\text { render + } \\
\text { aluminum } \\
\text { profiles }\end{array}$ & $\begin{array}{l}\text { Fiber } \\
\text { cement }\end{array}$ & Cedar \\
\hline
\end{tabular}

\begin{tabular}{|c|c|c|c|c|c|c|c|c|}
\hline \multirow[b]{4}{*}{ 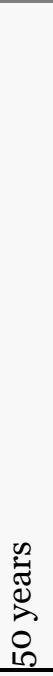 } & $\begin{array}{l}\text { Base } \\
\text { case }\end{array}$ & O\% & $-1 \%$ & o\% & o\% & o\% & $-2 \%$ & $-2 \%$ \\
\hline & $\begin{array}{l}\text { Low } \\
\text { generic } \\
\text { value }\end{array}$ & o\% & $-11 \%$ & o\% & o\% & o\% & $-31 \%$ & $-15 \%$ \\
\hline & $\begin{array}{l}\text { Standard } \\
\text { generic } \\
\text { value }\end{array}$ & o\% & $-26 \%$ & $-3 \%$ & $-1 \%$ & $-31 \%$ & $-2 \%$ & o\% \\
\hline & $\begin{array}{l}\text { High } \\
\text { generic } \\
\text { value }\end{array}$ & O\% & $-1 \%$ & o\% & o\% & o\% & $-4 \%$ & $-4 \%$ \\
\hline \multirow[b]{4}{*}{ 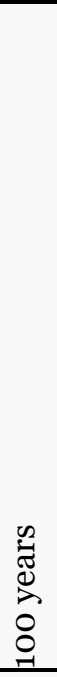 } & $\begin{array}{l}\text { Base } \\
\text { case }\end{array}$ & O\% & $-22 \%$ & o\% & 0\% & O\% & $-16 \%$ & $-15 \%$ \\
\hline & $\begin{array}{l}\text { Low } \\
\text { generic } \\
\text { value }\end{array}$ & O\% & $-24 \%$ & o\% & o\% & o\% & $-14 \%$ & $-13 \%$ \\
\hline & $\begin{array}{l}\text { Standard } \\
\text { generic } \\
\text { value }\end{array}$ & $-38 \%$ & $-43 \%$ & $-25 \%$ & $-12 \%$ & $-16 \%$ & $-16 \%$ & o\% \\
\hline & $\begin{array}{l}\text { High } \\
\text { generic } \\
\text { value }\end{array}$ & O\% & $-11 \%$ & $-2 \%$ & $-1 \%$ & o\% & $-23 \%$ & $-17 \%$ \\
\hline \multirow[b]{4}{*}{ 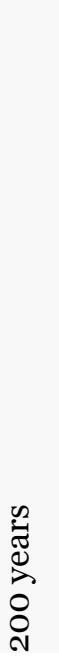 } & $\begin{array}{l}\text { Base } \\
\text { case }\end{array}$ & O\% & $-37 \%$ & o\% & o\% & o\% & $-14 \%$ & $-13 \%$ \\
\hline & $\begin{array}{l}\text { Low } \\
\text { generic } \\
\text { value }\end{array}$ & O\% & $-16 \%$ & o\% & o\% & o\% & o\% & $-4 \%$ \\
\hline & $\begin{array}{l}\text { Standard } \\
\text { generic } \\
\text { value }\end{array}$ & $-17 \%$ & $-24 \%$ & $-10 \%$ & $-6 \%$ & o\% & $-14 \%$ & o\% \\
\hline & $\begin{array}{l}\text { High } \\
\text { generic } \\
\text { value }\end{array}$ & $-34 \%$ & $-24 \%$ & $-14 \%$ & $-7 \%$ & O\% & $-5 \%$ & $-14 \%$ \\
\hline
\end{tabular}




\subsection{LCA using the annualized method}

The previous analyses used the round-up method to calculate the impact of maintenance and replacements. A third analysis was carried out with the annualized method to investigate to what extent the choice of method would influence the results. The relative difference in life cycle GWP when using the annualized method instead of the round-up method is reported in Table 3.

In every single case, the calculated GWP with the annualized method is smaller than with the round-up method. This is expected considering that, mathematically, the number of operations with the annualized method is always lower or equal to the round-up number of operations. In some cases, GWP is the same regardless of the choice of method. This is the case when there is no replacement operation (e.g., brick scenarios over a 50-year RSP) and when the RSP is a multiple of the replacement periods (e.g., fiber cement panels have a 50 -year service life in the base case, so the number of replacements is the same over 50,100, and 200 years regardless of the choice of method). However, in some cases, there is a significant difference in calculated GWP depending on the choice of method. This is the case when a major replacement happens shortly before the end of the RSP. For instance, for the non-ventilated render façade using standard generic service lives, a full replacement happens after 90 years. This operation contributes to almost half of the life cycle GWP calculated with the round-up method, but in the annualized method, only one-ninth of the impact of this operation is accounted for.

\section{Discussion}

\subsection{Significance of GWP from maintenance and replacement over different RSPs}

The present study indicates that maintenance and replacement processes for the various façade alternatives have a small relative contribution to life cycle GWP over 50 years in the base scenario $(0-17 \%$; the higher value is linked to repainting for the pine façade). However, their contribution is very significant over longer RSPs and when using more pessimistic assumptions about service lives. Over 100 years, the impact of maintenance and replacement is higher than all other stages of the life cycle combined for the pine façade and significant for the cedar, fiber cement, and non-ventilated render façades. Using the "low" and "standard" service lives from Erlandsson and Holm (2015), these processes are almost always significant and are often the main hotspot of GWP over 100 or 200 years. Nevertheless, the results also indicate that the initial production of some materials can still be the main contributor to GWP even over long RSPs. This is the case for bricks (in the base case) and for aluminum profiles. In the latter case, it is noteworthy that life cycle GWP can exhibit large differences between two variants of the same façade produced by the same company, due entirely to a difference in the material used for profiles.

Comparison with previous results is complicated by the fact that many published LCA studies of façades exclude the impacts of maintenance and replacement (e.g., Loussos et al. 2015; Saleem et al. 2018) or do not report them separately (e.g., Radhi and Sharples 2013; Taborianski and Prado 2012), and many studies focusing on maintenance and replacement do not focus on façade materials (e.g., Goulouti et al. 2020). Of the studies that offer suitable comparisons, Pomponi et al. (2015) find that maintenance operations (not including replacements) account for up to $9 \%$ of GWP of double skin façades over 50 years and Wadel et al. (2013) found that maintenance and replacement operations accounted for about a third of GWP over 50 years for a lightweight modular façade, a curtain wall and a traditional masonry façade. The base case in the present study showed lower shares of GWP attributed to maintenance and replacement, but when using standard generic service life data, the present study showed even higher contributions from maintenance and replacement for some alternatives over 50 years, up to $42 \%$ for fiber cement.

For some façade materials, maintenance and replacement processes might be considered of little importance in LCA calculations with a RSP of 50 years, which are common practice in many countries. However, over longer RSPs, these processes might be important hotspots of GWP, significant enough to influence the ranking of alternatives. For instance, the pine panels would be preferred over non-ventilated render with a 50-year RSP, but the opposite is true with a 100 years RSP (although the cedar clapboard panels displayed the lowest GWP in all scenarios). Over a long RSP, parameters such as service lives can become particularly sensitive and maintenance and replacement can become key issues on a GWP mitigation agenda. Using a longer RSP would encourage the use of durable, low-maintenance materials, while choosing a short RSP has the benefit of minimizing uncertainty and encouraging an earlier reduction of emissions (considering that the timing of emissions matters to determine their actual impact on the climate, see, e.g., Collinge et al. 2012; Levasseur et al. 2010; Su et al. 2017). In particular, using a short RSP minimizes uncertainties regarding future scenarios, e.g., potential future changes in production technologies or standards (which have not been considered in the present study).

Choosing a RSP in building LCA remains a controversial topic, as different studies and different LCA schemes use different RSPs. Results from the study were presented to stakeholders, and property managers commented that 


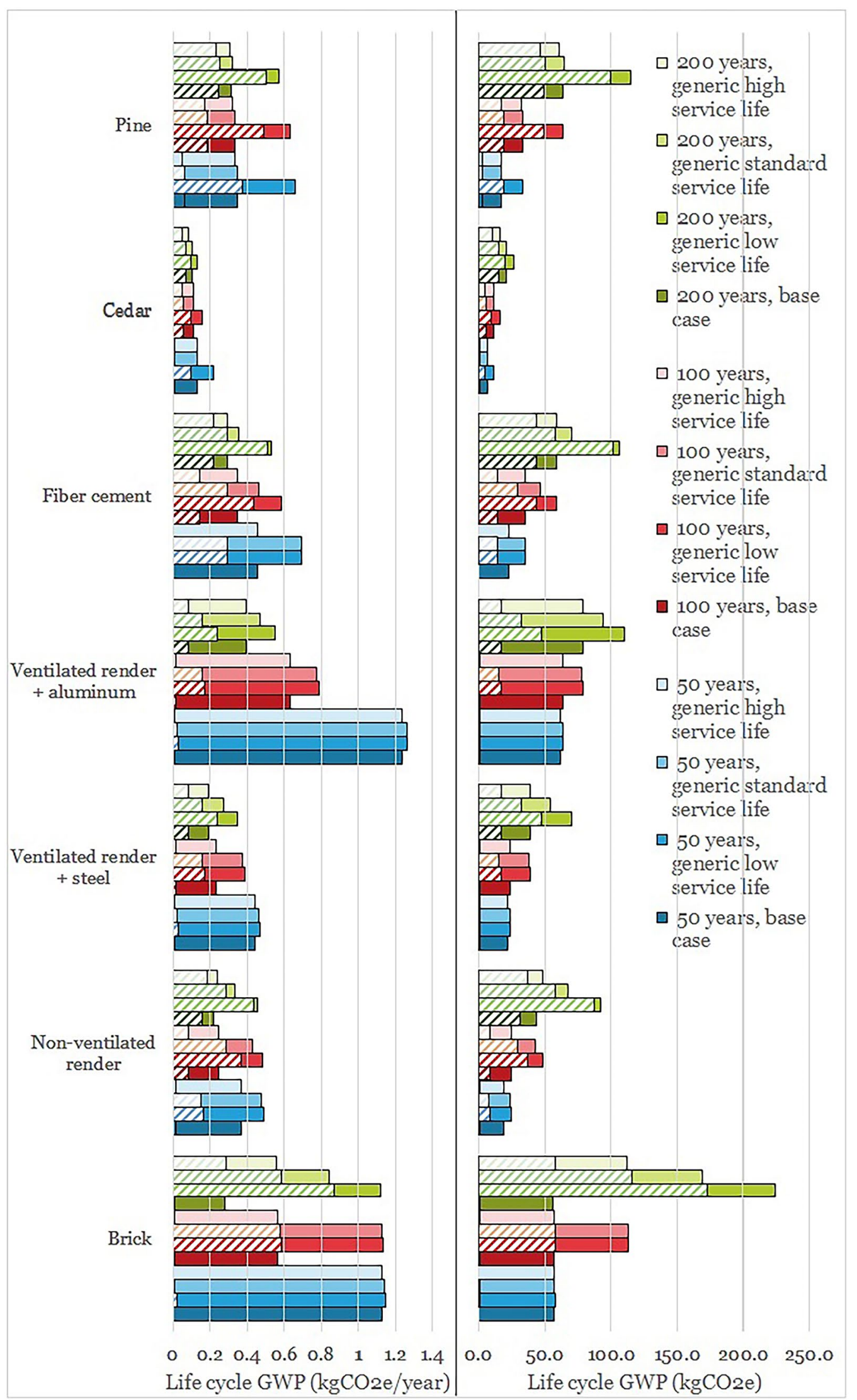


४Fig. 4 Life cycle GWP using generic service lives from the literature compared to the base case using service lives from manufacturers and technical documentation. The hashed area represents the contribution of modules B2-B4; the filled area represents all other modules

the RSPs they use in cost calculations are longer than the 50 years commonly used in LCA, which they saw as a challenge to the adoption of LCA. Estimating a building's service life is difficult: While many buildings remain standing beyond a 50-year operation period, some buildings are demolished before the end of their technical service life due to economic or social factors (Huuhka and Lahdensivu 2016). Huuhka and Lahdensivu (2016) showed that the average age at the time of demolition was 58 years for residential buildings and 43 years for nonresidential buildings in Finland, while Rincón et al. (2013) estimate the service life of dwellings in Spain to 80 years in average, with discrepancies between regions. However, the end of the RSP does not necessarily mean that the building is demolished. It might instead start a new life cycle, for instance after undergoing refurbishment. In Sweden, many residential buildings from the 1960s and 1970s are in need of refurbishment after around 50 years of operation (Swedish National Board of Housing Building and Planning 2010; Nägeli et al. 2019). Building elements with service lives longer than the RSP might be reused in this new life cycle. The present study accounts for $100 \%$ of the impacts of elements that might remain in use at the end of the RSP, but other approaches exist to allocate impacts between several life cycles for reused components (Eberhardt et al. 2020). This could be a way to account for the remaining value of durable elements at the end of the RSP and incentivize both the use of durable materials and the reuse of materials during refurbishment.

\subsection{Choice of data source for service lives}

The relative significance of maintenance and replacement processes and the ranking of alternatives depend on the chosen source of service life data. For instance, the pine façade ranked fourth and sixth over 100 and 200 years respectively when using service lives from manufacturers, but it ranked second and third over the same RSPs when using standard generic service lives. The brick façade ranked fourth over 200 years when using service lives from manufacturers, but it ranked seventh when using any of the generic service lives.

For some materials, there were very large discrepancies between different sources for service life data, which leads to considerable differences in calculated GWP over longer RSPs depending on which data source the LCA practitioner uses. It is noteworthy that the service lives obtained from practitioners and technical documentation were always higher or equal than the standard generic service lives. In particular, the difference in service lives for bricks is extremely large and considerably influences the results over a 200 years RSP. It is possible that some material manufacturers exaggerated the durability of their products. It is also possible that the report on generic service lives by Erlandsson and Holm (2015) underestimates service lives for particularly durable products, perhaps because LCAs in Sweden are most often carried out using a 50-year RSP (and therefore, little attention is paid to material service lives longer than the RSP). Practitioners from the brick and mortar industry reacted when presented with this result, claiming that the low and standard generic service lives for bricks were unrealistically low. Practitioners also disagreed with each other in some respects, showing, e.g., contradictory opinions regarding the frequency of repointing. In practice, a full replacement of a brick cladding is a rare scenario. It does happen in cases where the façade suffers unforeseen damage or the building undergoes extensive renovation. Besides arbitrary replacements due to changes in ownership, such replacements have for instance happened following changes in the building code leading to a need to install additional insulation behind the façade, or in cases where the loadbearing wall suffers moisture damage and the façade must be removed to access it. These replacements are not caused by a deterioration of the technical properties of the brick cladding itself, it can therefore be argued that they should not be included in module B4 (in the EN 15978 terminology). Refurbishment operations are normally addressed in module B5, but the boundaries between these modules are sometimes ambiguous and module B5 is rarely covered in LCA studies. Including a full replacement of a brick cladding could be seen as an attempt to account for such unforeseen operations. Moreover, the reality of maintenance and replacement operations differs sometimes from the regular intervals modeled in the present study. In particular, actual replacement operations are often opportunistic: multiple renovation measures are carried out at the same time to save on costs and administrative procedures (Farahani et al. 2019).

In a conference paper predating this study (Francart and Malmqvist 2020), statistical distributions of service lives for roofing materials were used to carry out a Monte Carlo analysis, based on data from Dixit (2018) and Hoxha et al. (2014). However, for some materials, standard deviations in the aforementioned sources are extremely high, indicating high variability in service life data found in the literature. In this case, statistical data might not be of high enough quality to draw far-reaching conclusions.

All these observations indicate a need for better data on the frequency of maintenance and replacement operations, dependent on exposure and use conditions. A recent paper by Goulouti et al. (2020) already offers improvements by proposing a statistical treatment of uncertainties related to service lives, based on the Swiss service life database DUREE. 
Another recent study by Silva and de Brito (2021) further explores this issue through a comprehensive critical review of available service life data for various building elements.

\subsection{Choice of calculation method for replacements}

Another contribution of the present study is the investigation of differences linked to the choice of method to calculate the impact of maintenance and replacement. When using the annualized method, GWP evolves linearly with service life. On the other hand, when using the round-up method, a small change in service life can sometimes lead to no change at all in calculated GWP and sometimes to dramatic changes. The difference is linked to the remaining service life of replaced materials at the end of the RSP: for a replaced element with two-thirds of its service life remaining at the end of the RSP, the annualized method will only account for one third of the impacts. In some schemes, the round-up method is combined with a criterion to ignore operations happening shortly before the end of the building's service life. For instance, the Danish LCAbyg tool ignores replacement operations if they happen in the last 10 years of the building's service life or if the new product's service life would exceed the remaining building service life by two-thirds (Birgisdottir and Nygaard Rasmussen 2019). The EN 15978 norm does not give such specific criteria, but recommends a critical consideration of the likelihood of replacement operations close to the end of the building's service life (European Standards 2011).

In the present study, differences in calculated GWP between the annualized and the round-up method are small in many cases. However, when a replacement operation with a large impact happens shortly before the end of the RSP, the annualized method leads to considerably lower calculated GWP. Goulouti et al. (2020) mention that the mean value of GWP calculated with the round-up method would be about $16 \%$ higher than when calculated with the annualized method. However, the present study shows that the issue is not necessarily about the sensitivity of calculated GWP to the choice of replacement method in average, but rather about particular situations where the choice of calculation method can significantly influence the results. For instance, with a 100-year RSP and standard generic service lives, pine ranks second and non-ventilated render ranks fourth when using the round-up method, but their respective ranks are switched when using the annualized method. This indicates a need to harmonize methodological choices to ensure that building LCA results are comparable.

\subsection{Limitations of the study}

A comprehensive interpretation of the results of this LCA study also requires a discussion of its limitations. A first limitation is the fact that the functional unit considered for the study includes the thermal performance of the façade, but not, e.g., its acoustic performance or thermal mass. In that regard, the different façade alternatives fulfill somewhat different functions. Moreover, the LCA was limited to GWP. GWP has sometimes been used as a proxy for other environmental impact categories, but in some cases, other impact categories correlate poorly with GWP (Heinonen et al. 2016; Laurent et al. 2012). A previous review suggests that, for some materials, maintenance and replacement processes might lead to a small GWP but a higher impact in other categories, such as resource depletion, primary energy use, human toxicity, particulate matter emission, or photochemical ozone formation (Francart and Malmqvist 2020).

There are also limitations linked to the choice of environmental data. In particular, there is considerable variability in emission factors for wood products. The values used for pine and cedar panels in this study are probably comparable with each other, as they are taken from EPDs from the same manufacturer. EPD data are used to represent the assessed product as specifically as possible. However, for the purpose of discussion and to assess the representativeness of the results, these values were compared with emission factors from other sources. The Ökobau database emission factors are 23\% higher for cedar and 33\% lower for pine. More problematic, values found in the Ecoinvent database and the Swedish LCA tool Byggsektorns Miljöberäkningsverktyg are an order of magnitude lower than the values used in the present study. Values from other wood product EPDs are found at both extremes. Discrepancies may be partly explained by actual differences between the processes represented in different sources (e.g., heat for drying or end of life scenario), but there is a need to ensure that the environmental data used in an assessment are based on a consistent method. Another issue with environmental data lies in the calculation of carbon uptake via carbonation in cementcontaining products. Data on carbon uptake via carbonation was missing in several of the EPDs used in this project, and the uptake was instead estimated by hand, using guidelines from EN 16,757, Product Category Rules for concrete and concrete elements, Annex BB (European Committee for Standardization, 2017, 2019). More details on the choice of environmental data and the calculation methods used can be found in supplementary material.

\section{Conclusion}

As building LCA tools enter mainstream practices and regulation, there is a need to harmonize LCA approaches. Different countries, certification systems, and tools use different methodological approaches and background data, which might lead to incomparable outcomes and inconsistent recommendations. Many LCA tools and schemes consider 
a full-building scope and a RSP of 50 or 60 years, including, e.g., the EU framework Level(s), the DGNB system, and the French E + C- system (Dodd et al. 2021; French Ministry for the Ecological Transition and French Ministry for Territorial Cohesion 2017; German Sustainable Building Council 2018). In these conditions, maintenance and replacement might be disregarded due to the relatively short RSP and the comparatively large initial embodied GWP of the building frame. However, the present study showed that choices of RSP, calculation method, and data source for service lives can significantly influence assessment results, and maintenance and replacement processes can be very significant for certain materials. These aspects become potential practical issues with far-reaching consequences on industrial practices when they are implemented in widespread assessment systems for certification and regulation. This calls for the attention of practitioners and policymakers and for further efforts towards harmonizing LCA practices.

Overall, the choice of RSP determines the relative significance of maintenance and replacement processes. Using a longer RSP would promote the use of more durable and low-maintenance materials, but it would emphasize less the importance of an early reduction of emissions, and would increase uncertainty linked to future scenarios. Regarding the choice of service life data source, the study revealed considerable discrepancies for some materials between data obtained from manufacturers and generic data from the literature. As LCA enters design practice, regulation, and procurement, using transparent and reliable data is crucial. In the EU, the Level(s) system prescribes the use of the factor method described in ISO $15686-8$ to derive case-specific service lives. This calculation is primarily based on estimations by manufacturers. When such values are unavailable, third party generic data or default values provided in Level(s) may be used. However, choosing one of these data sources over another could lead to significantly different results. The systematic gathering of statistical service life data representing actual use cases, rather than design lifetimes, could enhance the reliability and transparency of the results and reduce the number of arbitrary choices when applying the factor method (Aktas and Bilec 2012).

The case study also revealed the limitations of using average sensitivity values when determining the significance of methodological issues such as the choice of service lives and calculation method. In particular, the choice between annualized and round-up replacements did not appear to be very significant in most cases, but in cases where a major replacement happened shortly before the end of the RSP, the two methods provided very different results. Therefore, even though a particular methodological choice might be of little significance in average, there might be specific cases where it makes a considerable difference. Here, the difference is linked to the remaining service life of replaced materials at the end of the RSP. If the round-up method is used, it would be appropriate to combine it with an allocation approach that accounts for the benefits of reuse after the end of the RSP, in order to incentivize the use and reuse of durable materials (Eberhardt et al. 2020).

The study focused on analyzing methodological differences in building LCA, primarily to inform the development and use of LCA tools and schemes in procurement, certification, and regulation. For industry practitioners, the results draw attention to the importance of adopting a life cycle perspective in sustainable building design and considering recurring embodied emissions linked to maintenance and renovation. This is particularly important for elements that have a small initial impact but are replaced often, such as carpets, paint, doors, and windows (Carlisle and Friedlander 2016; Colli et al. 2018; Eberhardt et al. 2019; I.-F. Häfliger et al. 2017; Junnila et al. 2006; Kofoworola and Gheewala 2009; Minne and Crittenden 2015; Rauf and Crawford 2015; Scheuer et al. 2003). When planning maintenance and renovation operations, it is important to consider the remaining value of materials, as replacing materials before the end of their service life entails unnecessary costs and environmental impacts. Optimization models could be used to schedule operations, minimizing both costs and embodied emissions (Farahani et al. 2019; Nägeli et al. 2019). However, the study shows existing discrepancies in service life data between different sources; it is therefore important to monitor actual maintenance and replacement intervals to improve the accuracy of models used.

Supplementary Information The online version contains supplementary material available at https://doi.org/10.1007/s11367-021-01985-z.

Acknowledgements The authors would like to thank Dr. Miklós Molnar for his assistance with technical questions related to brick and mortar construction, Dr. Martin Erlandsson and Prof. emeritus Mauritz Glaumann for their comments on environmental data for wood products, and Emma Kostenbader for her contribution to data gathering and to an early stage of model development.

Funding Open access funding provided by Royal Institute of Technology. This study was funded by the Swedish Energy Agency (project number 46881-1) and by Mur and Putsföretagen, the Swedish trade association for brick and mortar construction.

Data availability All data generated or analyzed during this study are included in this published article (and its supplementary information files).

Open Access This article is licensed under a Creative Commons Attribution 4.0 International License, which permits use, sharing, adaptation, distribution and reproduction in any medium or format, as long as you give appropriate credit to the original author(s) and the source, provide a link to the Creative Commons licence, and indicate if changes 
were made. The images or other third party material in this article are included in the article's Creative Commons licence, unless indicated otherwise in a credit line to the material. If material is not included in the article's Creative Commons licence and your intended use is not permitted by statutory regulation or exceeds the permitted use, you will need to obtain permission directly from the copyright holder. To view a copy of this licence, visit http://creativecommons.org/licenses/by/4.0/.

\section{References}

Aktas CB, Bilec MM (2012) Service life prediction of residential interior finishes for life cycle assessment. Int J Life Cycle Ass 17(3):362-371. https://doi.org/10.1007/s11367-011-0367-6

Alig M, Frischknecht R, Krebs L, Ramseier L, Stolz P (2020) LCA of climate friendly construction materials. Uster. Retrieved from https://treeze.ch/fileadmin/user_upload/downloads/ Publications/Case_Studies/Building_and_Construction/670_ LCA_constructionMaterials_1.5C_v1.4.pdf

Allacker K, Castellani V, Baldinelli G, Bianchi F, Baldassarri C, Sala S (2019) Energy simulation and LCA for macro-scale analysis of eco-innovations in the housing stock. Int J Life Cycle Ass 24(6):989-1008. https://doi.org/10.1007/s11367-018-1548-3

Anand CK, Amor B (2017) Recent developments, future challenges and new research directions in LCA of buildings: a critical review. Renew Sust Energ Rev 67:408-416. https://doi.org/10.1016/j.rser. 2016.09.058

Birgisdottir H, Moncaster A, Wiberg AH, Chae C, Yokoyama K, Balouktsi M, Malmqvist T (2017) IEA EBC annex 57 evaluation of embodied energy and CO2eq for building construction. Energ Buildings 154:72-80. https://doi.org/10.1016/j.enbuild.2017.08.030

Birgisdottir H, Nygaard Rasmussen F (2019) Development of LCAbyg: a national life cycle assessment tool for buildings in Denmark. IOP C. Ser Earth Env 290(1). https://doi.org/10.1088/1755-1315/ 290/1/012039

Blengini GA, Di Carlo T (2010) The changing role of life cycle phases, subsystems and materials in the LCA of low energy buildings. Energ Buildings 42(6):869-880. https://doi.org/10. 1016/j.enbuild.2009.12.009

Buyle M, Braet J, Audenaert A (2013) Life cycle assessment in the construction sector: A review. Renew Sust Energ Rev 26:379-388. https://doi.org/10.1016/J.RSER.2013.05.001

Carlisle S, Friedlander E (2016) The influence of durability and recycling on life cycle impacts of window frame assemblies. Int $\mathbf{J}$ Life Cycle Ass 21(11):1645-1657. https://doi.org/10.1007/ s11367-016-1093-x

Chastas P, Theodosiou T, Kontoleon KJ, Bikas D (2018) Normalising and assessing carbon emissions in the building sector: a review on the embodied $\mathrm{CO} 2$ emissions of residential buildings. Build Environm 130(August 2017), 212-226. https://doi.org/10.1016/j. buildenv.2017.12.032

Colli C, Bataille A, Antczak E, Buyle-Bodin F (2018) Life Cycle Assessment of a French Single-Family House Refurbishment: The "bat-Eco2" Case Study. Proc CIRP 69(May):160-165. https://doi. org/10.1016/j.procir.2017.11.043

Collinge WO, Deblois JC, Sweriduk ME, Landis AE, Jones AK, Schaefer LA, Bilec MM (2012) Measuring whole-building performance with dynamic LCA : a case study of a green university building. International Symposium on Life Cycle Assessment and Construction - Civil Engineering and Buildings, (1), 309 - 317. Retrieved from http://www.rilem.net/images/publis/ d4f355276200c59c1a6e91b794cfc7ca.pdf
Cuéllar-Franca RM, Azapagic A (2012) Environmental impacts of the UK residential sector: life cycle assessment of houses. Build Environm 54:86-99. https://doi.org/10.1016/j.buildenv.2012.02.005

De Wolf C, Pomponi F Moncaster A (2017) Measuring embodied carbon dioxide equivalent of buildings: a review and critique of current industry practice. Energ Build 140.https://doi.org/10.1016/j. enbuild.2017.01.075

Dixit MK (2018) Life cycle recurrent embodied energy calculation of buildings: a review. J Clean Prod 209:731-754. https://doi.org/10. 1016/j.jclepro.2018.10.230

Dodd N, Donatello S, Cordella M (2021) Level(s) indicator 1.2: life cycle global warming potential (GWP) (Publication version 1.1). Retrieved from https://susproc.jrc.ec.europa.eu/product-bureau// sites/default/files/2021-01/UM3_Indicator_1.2_v1.1_37pp.pdf

Eberhardt LCM, Birgisdóttir H, Birkved M (2019) Life cycle assessment of a Danish office building designed for disassembly. Build Res Inf 47(6):666-680. https://doi.org/10.1080/09613218.2018.1517458

Eberhardt LCM, van Stijn A, Nygaard Rasmussen F, Birkved M, Birgisdottir H (2020) Towards circular life cycle assessment for the built environment: a comparison of allocation approaches. IOP c Ser Earth Env 588:032026. https://doi.org/10.1088/1755$1315 / 588 / 3 / 032026$

Erlandsson M, Holm D (2015) Livslängdsdata samt återvinningsscenarion för mer transparenta och jämförbara livscykelberäkningar för byggnader. Stockholm

European Committee for Standardization (2017) EN 16757 - Sustainability of construction works - environmental product declarations - product category rules for concrete and concrete elements. Belgium, Brussels

European Committee for Standardization (2019) Carbonation and CO2 uptake in concrete (Technical report CEN/TR 17310). Belgium, Brussels

European Standards (2011) EN 15978:2011 Sustainability of construction works. Assessment of environmental performance of buildings. Calculation method. https://doi.org/10.3403/30204399

Farahani A, Wallbaum H, Dalenbäck JO (2019) The importance of life-cycle based planning in maintenance and energy renovation of multifamily buildings. Sustain Cities Soc 44(June 2018) :715725. https://doi.org/10.1016/j.scs.2018.10.033

Francart N, Malmqvist T (2020) Investigation of maintenance and replacement of materials in building LCA. IOP c Ser Earth Env 588:032027. https://doi.org/10.1088/1755-1315/588/3/032027

French Ministry for the Ecological Transition and French Ministry for Territorial Cohesion (2017) Référentiel « Energie-Carbone» pour les bâtiments neufs - Méthode d'évaluation de la performance énergétique et environnementale des bâtiments neufs, 74 . Retrieved from http://www.batiment-energiecarbone.fr/IMG/pdf/ referentiel-energie-carbone-methode-evaluation-2017-07-01.pdf

Frischknecht R, Birgisdottir H, Chae CU, Lützkendorf T, Passer A, Alsema E, Yang W (2019) Comparison of the environmental assessment of an identical office building with national methods. IOP C. Ser Earth Env 323(1). https://doi.org/10.1088/1755-1315/ 323/1/012037

Frischknecht R, Ramseier L, Yang W, Birgisdottir H, Chae CU, Lützkendorf T, Zara O (2020) Comparison of the greenhouse gas emissions of a high-rise residential building assessed with different national LCA approaches - IEA EBC Annex 72. IOP c Ser Earth Env 588(2):022029. https://doi.org/10.1088/1755$1315 / 588 / 2 / 022029$

German Federal Ministry of the Interior, Building and Community (2020) Ökobau database, release 2020-II. Retrieved December 22, 2020, from http://www.oekobaudat.de/en/database/databasesearch.html

German Sustainable Building Council (2018) DGNB Criteria for new construction. https://doi.org/10.3390/life4040745 
Goldstein B, Rasmussen FN (2017) LCA of buildings and the built environment. In Life cycle assessment: theory and practice (pp. 695-722). Springer International Publishing. https://doi.org/10. 1007/978-3-319-56475-3_28

Gomes V, Saade M, Lima B, Silva M (2018) Exploring lifecycle energy and greenhouse gas emissions of a case study with ambitious energy compensation goals in a cooling-dominated climate. Energ Buildings 173:302-314. https://doi.org/10.1016/j. enbuild.2018.04.063

Göswein V, Rodrigues C, Silvestre JD, Freire F, Habert G, König J (2020) Using anticipatory life cycle assessment to enable future sustainable construction. J Ind Ecol 24(1):178-192. https://doi. org/10.1111/jiec.12916

Goulouti K, Padey P, Galimshina A, Habert G, Lasvaux S (2020) Uncertainty of building elements' service lives in building LCA \& LCC: what matters? Build Environm 183(October 2019). https://doi.org/10.1016/j.buildenv.2020.106904

Grant A, Ries R, Kibert C (2014) Life cycle assessment and service life prediction: a case study of building envelope materials. J Ind Ecol 18(2):187-200. https://doi.org/10.1111/jiec.12089

Häfliger I-F, John V, Passer A, Lasvaux S, Hoxha E, Saade MRM, Habert G (2017) Buildings environmental impacts' sensitivity related to LCA modelling choices of construction materials. J Clean Prod 156:805-816. https://doi.org/10.1016/J.JCLEPRO. 2017.04.052

Hauschild MZ, Rosenbaum RK, Olsen SI (2017) Life cycle assessment: theory and practice. Springer International Publishing. https://doi.org/10.1007/978-3-319-56475-3

Heinonen J, Säynäjoki A, Junnonen J-M, Pöyry A, Junnila S (2016) Pre-use phase LCA of a multi-story residential building: can greenhouse gas emissions be used as a more general environmental performance indicator? Build Environm 95:116-125. https://doi.org/10.1016/J.BUILDENV.2015.09.006

Hong J, Shen GQ, Feng Y, Lau WST, Mao C (2015) Greenhouse gas emissions during the construction phase of a building: a case study in China. J Clean Prod 103:249-259. https://doi.org/10. 1016/j.jclepro.2014.11.023

Hoxha E, Habert G, Chevalier J, Bazzana M, Le Roy R (2014) Method to analyse the contribution of material's sensitivity in buildings' environmental impact. J Clean Prod 66:54-64. https://doi.org/10.1016/j.jclepro.2013.10.056

Hoxha E, Jusselme T, Andersen M, Rey E (2016) Introduction of a dynamic interpretation of building LCA results: the case of the smart living building in Fribourg, Switzerland. In Sustainable Built Environment (SBE) Regional Conference Zurich 2016. (pp. 310-314). https://doi.org/10.3218/3774-6

Huuhka S, Lahdensivu J (2016) Statistical and geographical study on demolished buildings. Build Res Inf 44(1):73-96. https://doi. org/10.1080/09613218.2014.980101

International Energy Agency (2013) Transition to sustainable buildings. https://doi.org/10.1787/9789264202955-en

IVL Swedish Environmental Institute (2018) Byggsektorns Miljöberäkningsverktyg (Swedish Building Sector Environmental Calculation Tool). Retrieved May 15, 2019, from https://www.ivl.se/sidor/varaomraden/miljodata/byggsektorns-miljoberakningsverktyg.html

Junnila S, Horvath A, Guggemos AA (2006) Life-cycle assessment of office buildings in Europe and the United States. J Infrastruct Syst 12(1):10-17. https://doi.org/10.1061/(ASCE)1076-0342(2006) $12: 1(10)$

Kellenberger D, Althaus H-J (2009) Relevance of simplifications in LCA of building components. Build Environm 44(4):818-825. https://doi.org/10.1016/J.BUILDENV.2008.06.002

Kofoworola OF, Gheewala SH (2008) Environmental life cycle assessment of a commercial office building in Thailand. Int J Life Cycle Ass 13(6):498-511. https://doi.org/10.1007/ s11367-008-0012-1
Kofoworola OF, Gheewala SH (2009) Life cycle energy assessment of a typical office building in Thailand. Energ Buildings 41(10):10761083. https://doi.org/10.1016/j.enbuild.2009.06.002

Laurent A, Olsen SI, Hauschild MZ (2012) Limitations of carbon footprint as indicator of environmental sustainability. Envir Sci Tech 46(7):4100-4108. https://doi.org/10.1021/es204163f

Lavagna M, Baldassarri C, Campioli A, Giorgi S, Dalla Valle A, Castellani V, Sala S (2018) Benchmarks for environmental impact of housing in Europe: definition of archetypes and LCA of the residential building stock. Build Environm 145(May):260-275. https://doi.org/10.1016/j. buildenv.2018.09.008

Levasseur A, Lesage P, Margni M, Deschênes L, Samson R (2010) Considering time in LCA: dynamic LCA and its application to global warming impact assessments. Envir Sci Tech 44(8):31693174. https://doi.org/10.1021/es9030003

Loussos P, Konstantinou T, van den Dobbelsteen A, Bokel R (2015) Integrating life cycle energy into the design of façade refurbishment for a post-war residential building in the Netherlands. Buildings 5(2):622-649. https://doi.org/10.3390/buildings5020622

Lucon O, Ürge-Vorsatz D, Zain Ahmed A, Akbari H, Bertoldi P, Cabeza L, Vilariño MV (2014) Buildings. In Climate change 2014: mitigation of climate change. Contribution of Working Group III to the Fifth Assessment Report of the Intergovernmental Panel on Climate Change. (pp. 671-738). Cambridge: Cambridge University Press. Retrieved from http://www.ipcc. ch/pdf/assessment-report/ar5/wg3/ipcc_wg3_ar5_chapter9.pdf

Mequignon M, Adolphe L, Thellier F, Ait Haddou H (2013) Impact of the lifespan of building external walls on greenhouse gas index. Build Environm 59:654-661. https://doi.org/10.1016/j.buildenv. 2012.09.020

Minne E, Crittenden JC (2015) Impact of maintenance on life cycle impact and cost assessment for residential flooring options. Int J Life Cycle Ass 20(1):36-45. https://doi.org/10.1007/ s11367-014-0809-Z

Nägeli C, Farahani A, Österbring M, Dalenbäck JO, Wallbaum H (2019) A service-life cycle approach to maintenance and energy retrofit planning for building portfolios. Build Environm 160(May):106212. https://doi.org/10.1016/j.buildenv.2019.106212

Peñaloza D, Erlandsson M, Falk A (2016) Exploring the climate impact effects of increased use of bio-based materials in buildings. Constr Build Mater 125:219-226. https://doi.org/10.1016/j.conbuildmat. 2016.08.041

Petrovic B, Myhren JA, Zhang X, Wallhagen M, Eriksson O (2019) Life cycle assessment of building materials for a single-family house in Sweden. Energy Proced 158:3547-3552. https://doi.org/ 10.1016/j.egypro.2019.01.913

Peuportier B, Thiers S, Guiavarch A (2013) Eco-design of buildings using thermal simulation and life cycle assessment. J Clean Prod 39:73-78. https://doi.org/10.1016/j.jclepro.2012.08.041

Pomponi F, Piroozfar PAE, Southall R, Ashton P, Pirozfar P, Farr ERP (2015) Life cycle energy and carbon assessment of double skin façades for office refurbishments. Energ Buildings 109:143-156. https://doi.org/10.1016/j.enbuild.2015.09.051

Pomponi F, Moncaster A (2016) Embodied carbon mitigation and reduction in the built environment - what does the evidence say? J Environ Manage. https://doi.org/10.1016/j.jenvman.2016.08.036

Radhi H, Sharples S (2013) Global warming implications of facade parameters: a life cycle assessment of residential buildings in Bahrain. Environ Impact Assess 38:99-108. https://doi.org/10. 1016/j.eiar.2012.06.009

Rauf A, Crawford RH (2015) Building service life and its effect on the life cycle embodied energy of buildings. Energy 79(C):140-148. https://doi.org/10.1016/j.energy.2014.10.093 
Rincón L, Pérez G, Cabeza LF (2013) Service life of the dwelling stock in Spain. Int J Life Cycle Ass 18(5):919-925. https://doi.org/10. 1007/s11367-013-0552-x

Roh S, Tae S, Kim R (2018) Analysis of embodied environmental impacts of Korea $\mathrm{n}$ apartment buildings considering major building materials. Sustainability 10(6). https://doi.org/10.3390/ su 10061693

Saleem M, Chhipi-Shrestha G, Andrade TB M, Dyck R, Ruparathna R, Hewage K, Sadiq R (2018) Life cycle thinking-based selection of building facades. J Archit Eng 24(4):04018029. https://doi.org/ $10.1061 /$ (asce)ae.1943-5568.0000333

Scheuer C, Keoleian GA, Reppe P (2003) Life cycle energy and environmental performance of a new university building: modeling challenges and design implications. Energ Buildings 35(10):10491064. https://doi.org/10.1016/S0378-7788(03)00066-5

Silva A, de Brito J (2021) Service life of building envelopes: a critical literature review. J Build Eng 44(February):102646. https://doi. org/10.1016/j.jobe.2021.102646

Silvestre JD, Silva A, de Brito J (2015) Uncertainty modelling of service life and environmental performance to reduce risk in building design decisions. J Civ Eng Manag 21(3):308-322. https://doi.org/ $10.3846 / 13923730.2014 .890649$

Standard Norge (2017) prNS 3720 Method for greenhouse gas calculations for buildings

Su S, Li X, Zhu Y, Lin B (2017) Dynamic LCA framework for environmental impact assessment of buildings. Energ Buildings 149:310-320. https://doi.org/10.1016/J.ENBUILD.2017.05.042

Swedish National Board of Housing Building and Planning (2010) Teknisk status i den svenska bebyggelsen - resultat från projektet BETSI (In Swedish). Retrieved from http://www.boverket.se/globalassets/ publikationer/dokument/2011/betst-teknisk-status.pdf
Swedish National Board of Housing, Building and Planning (2020) Utveckling av regler om klimatdeklaration av byggnader (Developing rules for environmental declaration of buildings). Karlskrona, Sweden. Retrieved from https://www.boverket.se/globalassets/publikationer/dokument/ 2020/utveckling-av-regler-om-klimatdeklaration-av-byggnader.pdf

Taborianski VM, Prado RTA (2012) Methodology of CO2 emission evaluation in the life cycle of office building façades. Environ Impact Asses 33(1):41-47. https://doi.org/10.1016/j.eiar.2011. 10.004

Thibodeau C, Bataille A, Sié M (2019) Building rehabilitation life cycle assessment methodology-state of the art. Renew. Sust. Energ Rev 103 (December 2018):408-422. https://doi.org/10. 1016/j.rser.2018.12.037

United Nations Environment Programme and International Energy Agency (2017) Towards a zero-emission, efficient, and resilient buildings and construction sector. Global Status Report 2017. Retrieved from https://www.worldgbc.org/sites/default/files/ UNEP188_GABC_en(web).pdf

United Nations Framework Convention on Climate Change (2015) Paris Agreement. Conference of the Parties on Its Twenty-First Session. (December) 32. https://www.FCCC/CP/2015/L.9/Rev.1

Vilches A, Garcia-Martinez A, Sanchez-Montañes B (2017) Life cycle assessment (LCA) of building refurbishment: a literature review. Energ Buildings 135:286-301. https://doi.org/10.1016/j.enbuild. 2016.11.042

Wadel G, Alonso P, Zamora JL, Garrido P (2013) Simplified LCA in skin design: the FB720 case. Int J Sust Build Technol Urban Dev 4(1):68-81. https://doi.org/10.1080/2093761X.2012.759890

Publisher's Note Springer Nature remains neutral with regard to jurisdictional claims in published maps and institutional affiliations. 